\title{
Взаимосвязь патологии сердечно-сосудистой системы и заболеваний тканей пародонта (обзор литературы)
}

\author{
Витовский Р. М. ${ }^{1,2}$, Мазур И. П. ${ }^{1}$, Слободяник М. В. ${ }^{1}$, Мартыщенко И. В. ${ }^{2}$ \\ ${ }^{1}$ Национальная медицинская академия последипломного образования \\ имени П. Л. Шупика МЗ Украины (Киев) \\ 2 ГУ «Национальный институт сердечно-сосудистой хирургии имени Н. М. Амосова» (Киев)
}

\begin{abstract}
В статье представлен обзор литературы, содержащей современные взгляды на этиологию и патогенез воспалительных заболеваний тканей пародонта, их связь с патологией сердечно-сосудистой системы. Приведены современные данные о роли пародонтопатогенной микрофлоры в инициации и развитии сердечно-сосудистых заболеваний. Патогенетическим звеном, усиливающим связь между сердечно-сосудистой патологией и заболеваниями тканей пародонта, является системная воспалительная реакция. Сопряженное течение соматической и стоматологической патологии требует от стоматологов и кардиологов совместных усилий по профилактике общих факторов риска.
\end{abstract}

Ключевые слова: заболевания тканей пародонта, сердечно-сосудистая патология, атеросклероз, инфекиионный эндокардит, пародонтопатогенная микрофлора.

Цель работы - анализ представленных в литературе исследований влияния воспалительных процессов в тканях пародонта на развитие и течение заболеваний сердечно-сосудистой системы, а также на осложнения после кардиохирургических вмешательств.

Взаимосвязь патологических процессов, развивающихся в различных органах и системах организма, остается одной из наиболее сложных и до конца не решенных проблем клинической медицины. Большинство исследователей признают тесную патогенетическую связь между воспалительными заболеваниями пародонта и общесоматической патологией. Сахарный диабет, остеопороз, язвенная болезнь желудка и двенадцатиперстной кишки, респираторные заболевания достоверно сочетаются с поражением тканей пародонтального комплекса [52]. Ведущими факторами данной синтопии являются нарушения метаболизма, гемодинамики, микроциркуляции, иммунологические и нейрорегуляторные изменения или сдвиги микробиоценоза.

В настоящее время дискутабельным остается вопрос о степени взаимовлияния воспалительных заболеваний пародонта и заболеваний сердечно-сосудистой системы. Мета-анализ исследований, изучающих взаимосвязь заболеваний пародонта с сердечно-сосудистыми заболеваниями, с очевидной ясностью демонстрирует тесную связь пародонтита и развития гипертонической болезни: соотношение рисков этого угрожающего жизни заболевания у людей с пародонтитом является довольно высоким - 16\% (p<0,0005) в возрасте от 40-60 лет [31]. Janket et al. выполнили мета-анализ девяти когортных исследований, в которых генерализованный пародонтит (ГП) рассматривался как фактор риска развития сердечно-сосудистых и цереброваскулярных заболеваний. Так, 19\% обследуемых пациентов с ГП имели повышенный риск таких патологий, 44\% из них составляли люди моложе 65 лет [33]. В 2009 году Alessandra Blaizot et al. провели более обширный мета-анализ имеющихся исследований для изучения связи между пародонтитом и сердечно-сосудистыми заболеваниями. Исследования, опубликованные в период с 1989 по 2007 год (около двух десятилетий), получены путем электронного и ручного поиска из семи баз данных. Было достоверно установлено, что пациенты с генерализованным пародонтитом имеют более высокий риск развития сердечно-сосудистых заболеваний (34\%) по сравнению с теми, у кого нет заболеваний тканей пародонта $(\mathrm{p}<0,0001)$ [5]. Многочисленные исследования и данные ретроспективных наблюдений, полученных в последние десятилетия, продемонстрировали корреляцию между неудовлетворительным состоянием полости рта и риском развития инфаркта миокарда и ишемического инсульта [53].

Сердечно-сосудистые заболевания имеют многофакторную этиологию, тесно сопряженную с особенностями образа жизни и факторами риска (ФР) - куренем, нездоровым питанием, избыточной массой тела, артериальной гипертензией (АГ), возрастом, психосоциальными факторами и рядом других. Факторами риска для заболеваний тканей пародонта наряду с возрастом являются мужской пол, сахарный диабет I и II типа, курение, отягощенная наследственность и стресс. Таким образом, обе группы заболеваний имеют 
ряд идентичных факторов риска. В то же время вопрос взаимоотягощающего воздействия обеих патологий до настоящего времени окончательно не решен. При этом в исследованиях, посвященных изучению патогенеза этих состояний, прослеживается немало общих патогенетических изменений, что позволяет предположить вероятность раннего вовлечения в патологический процесс тканей пародонта с высокой частотой развития у больных с сердечно-сосудистой патологией (ССП).

В настоящее время заболевания пародонта представляют собой сложную проблему, что связано прежде всего с высокой распространенностью и интенсивностью поражения тканей вокруг зуба. Наибольшей распространенностью среди воспалительных заболеваний пародонта отличается генерализованный пародонтит, который является дистрофически-воспалительным процессом, возникающим вследствие сочетанного воздействия различных экзо- и эндогенных факторов. Этиологические факторы болезней пародонта подразделяются на локальные и системные. К локальным относятся те, которые действуют непосредственно в тканях пародонта, тогда как системные зависят от общего состояния пациента. Ведущим локальным фактором этиопатогенеза считаются воспалительные реакции, спровоцированные специфическими бактериями зубного налета, которые находятся в микробной биопленке. Она представлена специализированной бактериальной экосистемой, которая окружена защитным матриксом, не позволяющим проникать антибактериальным препаратам из слюны или десневой жидкости вовнутрь микробной биопленки [50]. Поэтому микроорганизмы в бактериальной экосистеме более устойчивы к антибиотикам и антимикробным средствам [50]. Накопление биопленки способствует прогрессированию патологических процессов, образованию пародонтальных карманов [1].

Роль микробной флоры полости рта в развитии сердечно-сосудистой патологии

Основным этиологическим фактором заболеваний тканей пародонта являются микроорганизмы зубной бляшки и продукты их жизнедеятельности (эндотоксины). Усиление патогенного потенциала микроорганизмов происходит на фоне реализации комплекса факторов, как местных (ретенция зубной бляшки), так и общих механизмов защиты (имунновоспалительный ответ), определяющих сопротивляемость тканей пародонта к патогенным воздействиям. При отсутствии хорошей индивидуальной гигиены толщина зубного налета увеличивается, изменяется микробный пейзаж, накапливаются продукты жизнедеятельности микроорганизмов. Микробный пейзаж может составлять более 500 видов бактерий. Накопление биопленки обусловливает воспаление и увеличение объема жидкости в зубодесневой борозде. Образовавшийся пародонтальный карман обеспечивает питательными веществами бактерии и улучшает рост анаэробных грамотрицательных бактерий, причастных к разрушению тканей пародонта. Пародонтопатогенная микрофлора в полости рта активирует систему комплемента, стимулирует продукцию простагландинов, лейкотриенов, интерлейкинов. Повышенная миграция макрофагов и лимфоцитов в очаг поражения обусловливает иммунологические реакции с участием цитокинов. Повышенное содержание простагландинов, цитокинов интерлейкин-6 (IL - 6), интерлейкин-1 $\beta$ (IL-1 $1 \beta$ ), фактор некроза опухолей- $\alpha$ $(\mathrm{TNF}-\alpha)$ в десневой жидкости провоцирует процессы деструкции костной ткани путем активации остеокластической резорбции [1]. Систематический обзор исследований предоставил данные о микроорганизмах полости рта, имеющих вирулентные факторы, в частности Aggregatibacter actinomycetemcomitans (Vander Reijden et al., 2008; Dileepan et al.,2007; Venketaraman et al., 2008; Fine et al., 2006), Tannerella forsythia, Porphyromonas gingivalis, Treponema denticola (Holt and Ebersole, 2005; Imamura, 2003; Kadowakietal, 2000; Nakayama, 2003; Potempa et al., 2003).

Гематогенный путь распространения микробной флоры из полости рта в органы и ткани организма

Стоматологические манипуляции сопровождаются кровоточивостью, что приводит к возможности проникновения микробной флоры в общий кровоток. Поэтому стоматологические манипуляции и оперативные вмешательства является фактором риска развития транзиторной бактериемии и, как результат, - системного инфекционного заболевания.

Транзиторная бактериемия характеризуется кратковременным наличием жизнеспособных бактерий в системном кровотоке. В результате травмирования слизистой оболочки в кровь попадают патогенные микроорганизмы, вызывающие вторичные очаги инфекции на значительном удалении от первичного очага инфицирования. На основании этого Американская ассоциация сердечно-сосудистых заболеваний (АНА) рекомендует антибиотикопрофилактику перед стоматологическими манипуляциями, сопровождающимися значительным кровотечением (пародонтальной хирургией, скейлингом и профессиональной гигиеной) в группах пациентов с высоким риском развития инфекционного эндокардита. Кроме того, в настоящее время в соответствии с Европейскими рекомендациями по лечению инфекционного эндокардита антибиотикопрофилактика проводится при стоматологических манипуляциях, связанных с экстракцией зуба или процедурами на периапикальных зонах зубов. Однако бактериемия наблюдается даже при отсутствии стоматологических вмешательств, во время индивидуальной гигиены, особенно у пациентов со значительным воспалением тканей пародонта. АНА констатирует, что «пациентам с 
риском инфекционного эндокардита (ИЭ) следует установить и поддерживать удовлетворительное состояние здоровья органов полости рта, чтобы сократить потенциальные источники бактериальной диссеминации». Это обусловило практику назначения антибиотиков для профилактики эндокардита до проведения инвазивных стоматологических вмешательств.

Рабочая группа Европейской Ассоциации Пародонтологии и Американской Академии Пародонтологии в 2013 году опубликовала результаты биологических и эпидемиологических исследований. Результаты исследований показали, что статистически значимые риски для развития заболеваний сердца и сосудов, независимые от установленных сердечно-сосудистых факторов риска, были у лиц с заболеваниями пародонта [8]. Ряд исследований подтвердил роль пародонтопатогенной микрофлоры в развитии этой патологии. В работе Forner et al. [20] было показано, что гематогенная распространенность микроорганизмов после ультразвукового скейлинга была значительно выше у пациентов с генерализованным пародонтитом по сравнению с пациентами с гингивитом и здоровыми людьми. У пациентов с пародонтитом величина бактериемии была связана с воспалением и количеством участков с кровоточивостью при зондировании пародонтального кармана. В исследованиях И. П. Мазур, Н. Л. Харченко [2], изучавших распространенность транзиторной бактериемии после стоматологических процедур, было продемонстрировано, что на 15-й минуте после проведения стоматологических манипуляций у 44,1\% пациентов зарегистрировано наличие патогенной микрофлоры в кровяном русле - Staphylococcus aureus $(16,3 \%)$, Staphylococcus pyogenes $(11,6 \%)$, Streptococcus viridans (14,0\%). На 30-й минуте после проведения стоматологических манипуляций у 16,2\% пациентов зарегистрировано наличие этой же патогенной микрофлоры в кровяном русле. Можно утверждать, что микроорганизмы из пародонтального кармана (Streptococcus viridans, Staphylococcus pyogenes, Staphylococcus aureus) и стоматологические манипуляции являются фактором риска развития транзиторной бактериемии.

В исследованиях Alka S. Waghmare et al. [6] было продемонстрировано, что до пародонтологического лечения частота выявления микроорганизмов в периферической крови составляла 7,5\%. Высокая обсемененность культур крови микроорганизмами была обнаружена сразу после пародонтологического лечения $-70 \%$, через 30 мин. показатели снизились до $25 \%$. В периферической крови высокая распространенность была у пародонтопатогена Porphyromonas gingivalis 37,5\%. Клинические исследования показали, что у 106 $(49,4 \%)$ из 219 анализируемых пациентов была положительная бактериемия. Более частыми бактериями были S. viridans, A. actinomycetemcomitans $P$. gingivalis, M. micros и виды Streptococcus и Actinomyces, хотя мето- ды идентификации микробиологических анализов в исследованиях были разными [2].

Существует также мнение, что микроорганизмы полости рта и их эндотоксины могут травмировать эндотелиальную стенку сосудов. Увеличивается количество доказательств того, что пародонтопатогенная микрофлора может непосредственно способствовать патогенезу атеросклероза путем повышения количества провоспалительных цитокинов, попадающих в кровоток [56]. Herzberg и его коллеги в своих исследованиях показали, что Streptococcus sanguis и Porphyromona gingivalis индуцируют агрегацию и активацию тромбоцитов посредством экспрессии коллагеноподобных белков. Агрегированные белки могут играть роль в формировании атеромы и образования тромба [45]. В последующей работе Haraszthy et al. идентифицировали пародонтопатогенную микрофлору в атеромах сонных артерий человека. После оперативного вмешательства (каротидной эндартерэктомии) на пятидесяти имеющихся атероматозных бляшках авторы с помощью ПЦР (полимеразной цепной реакции) идентифицировали наличие бактериальной $16 \mathrm{~S}$ рДНК, специфичной для пародонтопатогенных микроорганизмов. Тридцать процентов образцов были положительными для B. Forsythus, 26\% - для P. gingivalis, 18\% - для Aggregatibacter actinomyecetemcomitans и 14\% для P. intermedia [28].

Эти данные согласуются с результатами Р. J. Ford и соавторов, которые в образцах сонной артерии выявляли наличие P. Gingivalis в $100 \%$ обследуемых образцов, F. Nucleatum - в 84\%, T. Forsythia - в 48\%, Chlamydia pneumoniae - в 30\%, Helicobacter pylori и Haemophilus influenzae - в 4\%. В экспериментальной модели на животных инъекции $P$. gingivalis обусловили кальцификацию атеросклеротических бляшек на стенках сосудов. Увеличение продолжительности воздействия микроорганизма привело к увеличению атеросклеротических бляшек на стенках сосуда и большему сужению просвета [37]. В другом экспериментальном исследовании на животных Lalla et al. продемонстрировали, что инфицирование $P$. gingivalis привело к увеличению количества молекул адгезии сосудистых клеток 1 (VCAM-1), уровня сывороточного IL-6 и тканевого фактора [38]. В другом экспериментальном исследовании на кроликах было показано, что животные с экспериментально индуцированным пародонтитом имели более обширные скопления липидов в аорте по сравнению с группой животных со здоровыми тканями пародонта $(\mathrm{p}<0,05)$. Отмечалась положительная корреляция между тяжестью пародонтологического заболевания и степенью осаждения липидов [30]. На экспериментальной модели было показано, что P. gingivalis в высокой концентрации может индуцировать апоптотическую гибель эндотелиальных клеток сосудов (Roth et al., 2007).

Некоторые исследования показали, что пациенты с сердечно-сосудистыми заболеваниями имеют повы- 
шенные титры антител к пародонтопатогенным бактериям (Meurman et al., 2003; Mustapha et al., 2007).

Однако до сих пор нет четкого представления о взаимосвязи микрофлоры полости рта с инфекцией, провоцирующей поражение клапанного аппарата сердца.

\section{Взаимодействие микробной флоры полости рта с тромбоцитами крови}

В патогенезе генерализованного пародонтита (ГП) сушественную роль играют нарушения микроциркуляции, сопровождающиеся повышением сосудистотканевой проницаемости. В патогенезе расстройств микроциркуляции у больных ГП важная роль принадлежит нарушениям в сосудисто-тромбоцитарном и коагуляционном звеньях системы гемостаза, системы фибринолиза, реологических свойствах крови. Нарушения в микроциркуляторном звене гемостаза обусловлены изменениями процессов активации и агрегации тромбоцитов и тромборезистентности эндотелия сосудистой стенки. С увеличением тяжести ГП усиливается процесс активации и агрегации тромбоцитов, падает антиагрегационная, антикоагулянтная и фибринолитическая способность эндотелия сосудов. Атеросклероз сосудов также сопровождается выраженными микроциркуляторными нарушениями, изменениями антиагрегационных, антикоагулянтных и фибринолитических свойств эндотелия сосудов.

Следует отметить, что в настоящее время основная теория возникновения сепсиса - это эндотелиальная дисфункция. Важным аспектом влияния пародонтопатогенных бактерий на кровеносные сосуды является их способность реагировать и взаимодействовать с тромбоцитами крови. В то время как основная роль тромбоцитов - это гемостаз, они также играют определенную роль в иммунном ответе на инфекцию [56]. В исследованиях установлено, что многие виды Streptococci, особенно $S$. viridans, $S$. sanguinis, $S$. gordonii, $S$. mutans и $S$. mitis, способны индуцировать адгезию и агрегацию тромбоцитов in vitro (Kerrigan S. W., Cox D., 2010), что может приводить к дальнейшему формированию тромбоэмболий сосудов. Показано, что везикулы $P$. gingivalis индуцируют агрегацию тромбоцитов [57]. Везикулы это отростки наружной мембраны, содержащие много факторов вирулентности - таких, как гемагглютинины, протеазы и липополисахариды [30]. Предполагается, что с помощью фимбрий (жгутиков) бактерия P. gingivalis может зацепиться за тромбоцит, и тогда поверхностно экспрессирующиеся белки везикул (капсулы, содержащие многие вирулентные факторы) взаимодействуют с рецепторами тромбоцитов, что вызывает их последующую агрегацию [45]. В исследованиях было продемонстрировано, что с помощью фимбрий in vitro P. gingivalis вторгается также в эпителиальные клетки пародонтального кармана и эндотелиальные клетки, выстилающие стенку аорты [3]. В публикациях указа- но, что $P$. gingivalis вызывает агрегацию тромбоцитов через тол-подобные рецепторы (TLR-2) [44]. Агрегационная способность тромбоцитов $P$. gingivalis была продемонстрирована на модели животных. Искусственно созданный штамм $P$. gingivalis, имеющий фимбрии, был мощным активатором тромбоцитов у мышей, а мутант DPG3, не имеющий фимбрий, был неэффективен при индуцировании агрегации [52].

\section{Патогенетические механизмы взаимосвязи микро- флоры полости рта и сердечно-сосудистой патологии}

Многочисленные литературные данные дают основание полагать, что воспалительный процесс в пародонте может быть одной из причин развития другой, не менее распространенной патологии - атеросклероза. Некоторые исследователи приходят к выводу о патогенетической связи генерализованного пародонтита и атеросклероза с поражением аорты, коронарных артерий, периферических сосудов. По мнению ряда авторов, цитокины (IL-6, TNF- $\alpha$, IL-1) и другие медиаторы воспаления, продуцируемые клетками-респондерами, освобождаются при пародонтите и обладают способностью стимулировать гепатоциты для производства С-реактивного белка (СРБ). С-реактивный белок является одним из доказанных биохимических маркеров выраженной атеросклеротической эндотелиальной дисфункции.

Для проверки этой гипотезы проведен ряд экспериментальных и клинических исследований. Результаты исследований Bahekar et al. [10] показали, что пациенты с заболеванием тканей пародонта имеют достоверно более высокие показатели СРБ по сравнению с пациентами со здоровыми тканями пародонта $(\mathrm{p}<0,05)$. Результаты Salberz et al. [49] показали, что генерализованный пародонтит значительно связан с повышенными уровнями СРБ. Группа пациентов с генерализованным пародонтитом имела значительно повышенный уровень СРБ (3,72 мг/л) по сравнению с группой пациентов с диагнозом локализованный пародонтит (2,57 мг/л) и контрольной группой (1,54 мг/л) [49]. Кроме того, у пациентов с пародонтитом повышенный уровень СРБ в сыворотке ассоциируется с высоким уровнем инфицирования пародонтопатогенными микроорганизмами [46]. В исследованиях Dye et al. авторы увидели взаимосвязь между высоким уровнем титра в сыворотке крови к микроорганизму $P$. gingivalis и высоким уровнем показателей СРБ [48]. Напротив, титр A. actinomycetecomitans не был связан с высокими уровнями СРБ. Аналогичные результаты для P. gingivalis наблюдались также в исследованиях Pitiphat et al. [49]. Эти данные привлекли значительное внимание, поскольку они демонстрируют связь болезни тканей пародонта и повышенного уровня СРБ. Другие исследования показали, что пародонтологическое лечение может значительно снизить уровень СРБ в сыворотке 
крови [15]. Чтобы поддержать эту концепцию, D’Aiuto и др. провели исследование, в котором они наблюдали снижение сывороточного уровня СРБ после завершения пародонтологического лечения. Авторы пришли к выводу, что контроль пародонтита может быть достигнут с помощью нехирургического пародонтологического лечения, что значительно снижает уровень медиаторов и маркеров острого иммуновоспалительного ответа. Поскольку СРБ представляет собой острый фазовый белок, когда устраняется пародонтопатогенная микрофлора, запустившая иммуновоспалительную реакцию, уровень СРБ снижается [43].

В зарубежной литературе обозначена и иммунологическая гипотеза взаимосвязи хронической инфекции при пародонтите с сердечно-сосудистыми и нейроваскулярными заболеваниями. При генерализованном пародонтите происходит аутоиммунная реакция против антигенов бактерий. При этом увеличивается концентрация специфических IgA-антител к пародонтопатогенным микроорганизмам, что может повышать риск аутоиммунных реакций по отношению к эндотелию сосудов.

Выводы. На сегодняшний день проблема заболеваний пародонта остается в центре внимания исследователей и является актуальной в стоматологии в связи с широкой распространенностью. Основное место в структуре заболеваемости пародонта занимает генерализованный пародонтит, развитие которого связано с нарушением баланса микрофлоры полости рта и ослаблением функций местных и общих механизмов защиты организма.

Из представленных данных можно сделать вывод, что пародонтит приводит к более высоким системным уровням СРБ. Повышенные воспалительные факторы могут усиливать воспалительную активность при атеросклеротических поражениях и потенциально увеличивать риск сердечно-сосудистых заболеваний. Эти и другие исследования показывают, что пародонтопатогенная микрофлора может присутствовать в атеросклеротических бляшках, где, наряду с другими факторами риска, также играет определенную роль в атерогенезе. По-видимому, изменения, происходящие при ГП, способны усугублять гемореологические изменения, характерные для атеросклероза. Представленные данные свидетельствуют о способности пародонтопатогенной микрофлоры вызывать адгезию и агрегацию тромбоцитов, что может способствовать развитию и прогрессированию тромбозов кровеносных сосудов.

Накопленная в настоящее время доказательная база клинических и экспериментальных исследований не позволяет однозначно трактовать наличие воспалительных заболеваний пародонта как установленный фактор кардиоваскулярного риска. Но в то же время в международных протоколах, посвященных проблеме профилактики сердечно-сосудистых заболеваний, отмечается необходимость своевременного выявления и оптимальной кор- рекции пародонтита, как и других иммуновоспалительных заболеваний. Для точной оценки влияния заболеваний тканей пародонта на сердечно-сосудистые заболевания (в частности, клапанную патологию) необходимы исследования с участием больных, имеющих сочетанную патологию. С этой же целью необходимы исследования с регистрацией случаев заболевания тканей пародонта у пациентов с клапанной патологией.

\section{Литература}

1. Данилевский Н. Ф., Борисенко А. В. Заболевания пародонта. - К. : Здоров’я, 2000. - 464 с.

2. Мазур И. П., Харченко Н. Л. Микробиологический мониторинг транзиторной бактериемии у стоматологических больных // Дентальные технологии. 2010. - № 1 (44). - C. 10-13.

3. Variations of Porphyromonasgingivalis fimbriae in relation to microbial pathogenesis / Amano A., Nakagawa I., Okahashi N. et al. // J Periodont Res. - 2004. - Vol. 39. P. $136-42$.

4. Detection of Transient Bacteraemia following Dental Extractions by 16S rDNA Pyrosequencing: A Pilot Study / Alfonso BenHtez-Pбez, Maximiliano blvarez, Pedro BeldaFerre et al. // PLoS One. - 2013. - Vol. 8 (3). - e57782.

5. Silvestre FJ. Cardiovascular disease versus periodontal disease: Chronic systemic infection as a link / AlonsoGonzбlez R., Pŭrez-Hernøndez A., Silvestre-Rangil J. et al. // J ClinExpDent. - 2011. - Vol. 3. - e476.

6. Bacteremia following scaling and root planing: A clinicomicrobiological study / Alka S. Waghmare, Priyanka B. Vhanmane, B. Savitha et al. // J Indian Soc Periodontol. 2013 Nov-Dec. - Vol. 17 (6). - P. 725-730.

7. Dissemination of Periodontal Pathogens in the Bloodstream after Periodontal Procedures: A Systematic Revie / Anna Carolina Ratto Tempestini Horliana, Leandro Chambrone, Adriana Moura Foz et al. // PLoS One. - 2014. - Vol. 9 (5). - e98271.

8. Atherosclerotic cardiovascular diseases (ACVDs) are a leading cause of death and disability across the developed world and impose a vast burden on healthcare resources. This category of diseases includes / EFP \& MS Media Service [www.perioworkshop.org] / MAY 2013

9. Amano A. Disruption of epithelial barrier and impairment of cellular function by Porphyromonas gingivalis // Front Biosci. - 2007. - Vol. 12. - P. 3965-74. [PubMed]

10. The prevalence and incidence of coronary heart disease is significantly increased in periodontitis: a meta-analysis / Bahekar A. A., Singh S., Saha S. et al. // Am Heart J. 2007. - Vol. 154. - P. 830-7.

11. Periodontitis in coronary heart disease patients: strong association between bleeding on probing and systemic biomarkers / Bokhari S. A. H., Khan A. A., Butt A. K. et al. // J ClinPeriodontol. - 2014. - Vol. 41. - P. 1048- 1054.

12. Periodontal diseases and cardiovascular events: Metaanalysis of observational studies / Blaizot A., Vergnes J. N., Nuwwareh S. et al. // Int Dent J. -2009. - Vol. 59. P. 197-209. [PubMed]

13. Relationship between the oral cavity and cardiovascular diseases and metabolic syndrome / Carramolino- 
Cuйllar E., Tomбs I., Jimйnez-Soriano // Med Oral Patol Oral Cir Bucal. - 2014 May 1. - Vol. 19 (3). - e289-94.

14. Periodontitis may increase the risk of peripheral arterial disease / Chen Y. W. et al. // Eur J Vasc Endovasc Surg. 2008. - Vol. 35. - P. 153-8.

15. Periodontitis and atherogenesis: causal association or simple coincidence / D'Aiuto F., Parkar M., Andreaou G. et al. // J Clin Periodontol. - 2004. - Vol. 31. - P. 402-411.

16. Evidence that periodontal treatment improves biomarkers and CVD outcomes / D'Aiuto F., Orlandi M., Gunsolley J. C. // J Clin Periodontol. - 2013. - Vol. 40. P. 85-105.

17. Periodontitis and atherogenesis: causal association or simple coincidence / D’Aiuto F., Parkar M., Andreaou G. et al. // J Clin Periodontol. - 2004. - Vol. 31. - P. 402-11. [PubMed]

18. Serum antibodies to periodontal pathogens and markers of systemic inflammation / Dye B. A., Choudhary K., Shea S. et al. // J Clin Periodontol. - 2005. - Vol. 32. - P. 118999. [PubMed]

19. De Nardin E. The role of inflammatory and immunological mediators in periodontitis and cardiovascular disease // Ann Periodontol. - 2001. - Vol. 6. - P. 30-40.

20. Incidence of bacteremia after chewing, tooth brushing and scaling in individuals with periodontal inflammation / Forner L., Larsen T., Kilian M. / J Clin Periodontol. -2006 Jun. - Vol. 33 (6). - P. 401-7.

21. Increased plasma levels of IL-6 in bacteremic periodontitis patients after scaling / Forner L., Nielsen C. H., Bendtzen K. et al. // J Clin Periodontol. - 2006. - Vol. 33. - P. 724-729.

22. The interaction of bacterial pathogens with platelets / Fitzgerald J. R., Foster T. J., Cox D. // Nat Rev Microbiol. 2006. - Vol. 4. - P. 445-57. [PubMed]

23. Guidelines for the prevention of endocarditis: report of the Working Party of the British Society for Antimicrobial Chemotherapy / F. K. Gould1, T. S. J. Elliott, J. Foweraker et al. // Journal of Antimicrobial Chemotherapy. - 2006. Vol. 57. - P. 1035-1042.

24. Georg A. Roth, Bernhard Moser. Infection with a periodontal pathogen increases mononuclear cell adhesion to human aortic endothelial cells / Atherosclerosis. 2007. - Vol. 190. - P. 271-281;

25. Innate immune signaling and Porphyromonas gingivalis accelerated atherosclerosis / Gibson F. C., Yumoto H., Takahashi Y. et al. // J Dent Res. - 2006. - Vol. 85. P. 106-121.

26. Systemic release of endotoxins induced by gentle mastication: association with periodontitis severity / Geerts S. O., Nys M., De M. P. et al. // J Periodontol. 2002. - Vol. 73 (1). - P. 73-8.

27. Oral Inflammatory Diseases and Systemic Inflammation: Role of the Macrophage / Hatice Hasturk, Alpdogan Kantarci and Thomas E. Van Dyke // Front Immunol. 2012. - Vol. 3. - P. 118.

28. Identification of periodontal pathogens in atheromatous plaques / Haraszthy V. I., Zambon J. J., Trevisan M. et al. // Periodontol. - 2007. - Vol. 1. - P. 1554-60. [PubMed]

29. Guidelines on prevention, diagnosis and treatment of infective endocarditis executive summary the task force on infective endocarditis of the European Society of
Cardiology / Horstkotte D., Follath F., Gutschik E. et al. // Eur Heart J. - 2004. - Vol. 25. - P. 267-76.

30. Holt S. C., Ebersole J. L. Porphyromonas gingivalis, Treponema denticola and Tannerella forsythia: the "red complex", a prototype polybacterial pathogenic consortium in periodontitis // Periodontol. - 2000, 2005. - Vol. 38. P. 72-122.

31. Porphyromonas gingivalis ( $\mathrm{Pg})$ a possible link between impaired oral health and acute myocardial infarction / Holmlund A., Hedin M., Pussinen P. J. et al. // Int J Cardiol. - 2009. - Vol. 148. - P. 148-53.

32. Role for periodontitis in the progression of lipid deposition in an animal model / Jain A., Batista E. L. et al. // Infect. Immun. - 2003. - Vol. 71, 6012-601810.1128/ IAI.71.10.6012-6018.2003

33. Meta-analysis of periodontal disease and risk of coronary heart disease and stroke / Janket S. J., Baird A. E., Chuang S. K. et al. // Oral Surg Oral Med Oral Pathol Oral Radiol Endod. - 2003. - Vol. 95. - P. 559-69. [PubMed]

34. Periodontal disease, tooth loss, and incidence of ischemic stroke / Joshipura K. J. et al. // Stroke. - 2003. - Vol. 34. P. 47-52.

35. Bacteraemia following periodontal procedures / Kinane D. F., Riggio M. P., Walker K. F. et al. // J Clin Periodontol. - 2005 Jul. - Vol. 32 (7). - P. 708-13.

36. Bacteraemia following periodontal procedures / Kinane D. F., Riggio M. P., Walker K. F. et al. // J Clin Periodontol. - 2005. - Vol. 32 (7). - P. 708-13.

37. Role of periodontal bacteria in cardiovascular disease / Kuramitsu H. K., Qi M., Kang I. C. et al. // Ann periodontal. - 2001. - Vol. 6. - P. 41-7. [PubMed]

38. Oral infection with a periodontal pathogen accelerates early atherosclerosis in apolipoprotein E-null mice / Lalla E., Lamster I. B., Hofmann M. A. et al. // Arterioscler Thromb Vasc Biol. - 2003 Aug 1. - Vol. 23 (8). - P. 1405-11. Epub 2003 Jun 19.

39. Perio-dontal disease and atherosclerotic vascular disease: does the evidence support an independent asso-ciation: a scientific statement from the American Heart Association / Lockhart P. B., Bolger A. F., Papapanou P. N. et al. // Circulation. - 2012. - Vol. 125. - P. 2520-44.

40. Porphyromonas gingivalis-induced platelet aggregation in plasma depends on Hgp44 adhesin but not Rgp proteinase / Naito M., Sakai E., Shi Y. et al. // Mol. Microbiol. 2006. - Vol. 59 (1). - P. 152-167.

41. Periodontitis-associated up-regulation of systemic inflammatory mediator level may increase the risk of coronary heart disease / Nakajima T., Honda T., Domon H. et al. // J Periodont Res. - 2010. - Vol. 45. - P. 116-122.

42. State of the science: chronic periodontitis and systemic health / Otomo-Corgel J., Pucher J. J., Rethman M. P. et al. // J Evid Based Dent Pract. - 2012. - Vol. 12 (3 Suppl). - P. 20-8.

43. A systematic review and meta - analyses on $\mathrm{C}-$ reactive protein in relation to periodontitis / Paraskevas S., Huizinga J. D., Loos B. G. // J Clin Periodontal. - 2008. Vol. 35. - P. 277-90.

44. C-reactive protein associated with periodontitis in a Thai population / Pitiphat W., Savetsilp W., Wara-Aswapati N // J Clin Periodontol. - 2008. - Vol. 35. - P. 120-25. [PubMed] 
45. The link between periodontal disease and cardiovascular disease: How far we have come in last two decades? / Prasad Dhadse, Deepti Gattani and Rohit Mishra // J Indian Soc Periodontol. - 2010 Jul-Sep. - Vol. 14 (3). - P. 148-154.

46. Ramsdale D. R., Turner-Stokes L. Advisory Group of the British Cardiac Society Clinical Practice Committee et al. Prophylaxis and treatment of infective endocarditis in adults: a concise guide // Clin Med. - 2004. - Vol. 4. P. 545-50.

47. Reeves G. C-reactive protein // Aust Prescr. - 2007. Vol. 30. - P. 74-76.

48. IgG sera levels against a subset of periodontopathogens and severity of disease in aggressive periodontitis patients: acrosssectional study of selected pocket sites / Saraiva L., Rebeis E. S., Martins E. S. et al. // J Clin Periodontol. 2014. - Vol. 41. - P. 943-951.

49. C-reactive protein levels in patients with aggressive periodontitis / Salzberg T. N., Overstreet B. T., Rogers J. D. et al. // J Periodontol. - 2006. - Vol. 77. - P. 933-39. [PubMed]

50. Microbiological parameters associated with IL-1 gene polymorphisms in periodontitis patients / Socransky S. S., Haffajee A. D., Smith C. et al. // J Clin Periodontol. 2000. - Vol. 27. - P. 8108.

51. Activation of human gingival epithelial cells by cell-surface components of blackpigmented bacteria: mentation of production of interleukin-8, granulocyte colonystimulation factor and granulocyte-macrophage colonystimulation factor and expression of intercellular adhesion molecule 1 / Sugiyama A., Uehara A., Matsushita K. et al. // Bact Pathogen. - 2002. - Vol. 51. - P. 27-33.

52. Porphyromonasgingivalis platelet aggregation activity: outer membrane vesicles are potent activators of murine platelets / Sharma A., Novak E. K., Sojar H. T. et al. // Oral Microbiol. Immunol. - 2000. - Vol. 15 (6). - P. 393-396.

53. Taguchi A. Association between Oral Health and the Risk of Lacunar Infarction in Japanese Adults / A. Taguchi, M. Miki, A. Muto [et al.] // Gerontology. - 2013. - Vol. 59, № 6. - P. 499-506.

54. Periodontal disease and risk of cerebrovascular disease: The First National Health and Nutrition Examination Survey and its follow-up study / Wu T. et al. // Arch Intern Med. 2000. - Vol. 160. - P. 2749-55.

55. Wozakowska-Kaplon B. Oral health status and the occurrence and clinical course of myocardial infarction in hospital phase: A case-control study / B. WozakowskaKaplon, M. Wosowicz, I. Gorczyca-Michta et al. // Cardiol. J. - 2013. - Vol. 20, № 4. - P. 370-377.

56. Prevotella nigrescens and Porphyromonas gingivalis are associated with signs of carotid atherosclerosis in subjects with and without periodontitis / Yakob M., Sцder B., Meurman J. H. et al. // J Periodontal Res. - 2011. Vol. 46. - P. 749-55.

57. Porphyromonas gingivalis induces myocarditis and/or myocardial infarction in mice and IL-17A is involved in pathogenesis of these diseases / Yuki Akamatsu, Toshiro Yamamoto et al. // Archives of oral biology. - 2011. Vol. 56. - P. 1290-1298.

\title{
Interrelation of cardiovascular pathology and periodontal disease
}

Vitovsky R. M. ${ }^{1,2}$, Mazur I. P. ${ }^{1}$, Slobodyanik M. V. ${ }^{1}$, Martyshchenko I. V. ${ }^{2}$

${ }^{1}$ National P. L. Shupyk Medical Academy of Postgraduate Education (Kyiv)

${ }^{2}$ National M. M. Amosov Institute of Cardiovascular Surgery National Academy of Medical Sciences of Ukraine (Kyiv)

The article contains a review of literature on current views on the etiology and pathogenesis of inflammatory diseases of periodontal tissues, their relationship to the pathology of the cardiovascular system. Presented modern data on the role of parodontopathogenic microflora in the initiation and development of cardiovascular diseases. Pathogenetic link, which strengthens the connection between cardiovascular pathology and periodontal tissue diseases, is a systemic inflammatory reaction. The conjugate course of somatic and dental pathology requires joint efforts from dentists and cardiologists to prevent common risk factors.

Key words: periodontal tissue diseases, cardiovascular pathology, atherosclerosis, infective endocarditis, parodontopathogenic microflora.

\section{Взаємозв’язок серцево-судинної патології та захворювань тканин пародонта}

\author{
Вітовський Р. М. ${ }^{1,2}$, Мазур І. П. ${ }^{1}$, Слободяник М. В. ${ }^{1}$, Мартищенко І. В. ${ }^{2}$ \\ ${ }^{1}$ Національна медична академія післядипломної освіти імені П. Л. Шупика МОЗ України (Київ) \\ ${ }^{2}$ ДУ «Національний інститут серцево-судинної хірургії імені М. М. Амосова НАМН» (Київ)
}

У статті представлено огляд літератури, яка містить сучасні погляди на етіологію та патогенез запальних захворювань тканин пародонта, їх зв'язок із патологією серцево-судинної системи. Наведено сучасні дані про роль пародонтопатогенної мікрофлори в ініціації та розвитку серцево-судинних захворювань. Патогенетичною ланкою, що підсилює зв'язок між серцево-судинною патологією та захворюваннями тканин пародонта, є системна запальна реакція. Поєднаний перебіг соматичної та стоматологічної патології потребує від стоматологів і кардіологів спільних зусиль із профілактики загальних факторів ризику.

Ключові слова: захворювання тканин пародонта, серцево-судинна патологія, атеросклероз, інфекційний ендокардит, пародонтопатогенна мікрофлора. 